\title{
Design and Study on Exploration Data Management System on MapGIS
}

\author{
Ye CHEN, Wenyou FAN \\ China University of Geosciences, Faculty of Information Engineering HuBei WuHan \\ E-mail: littleaf@163.com
}

\begin{abstract}
A large quantity of data in earthquake, well-log, grilling, geology and other non-seismic geophysics, has been accumulated during long period of petroleum prospecting. These data are stored in papery document and managed in low efficient manual management. This paper proposed this petroleum exploration information management system which adopts SQL Server2000 as database server and combines B/S and C/S model based on MapGIS. By the combination of data layer, management layer and application layer, it realized exploration information management and sharing. The experimental experience shows that this system ensures the exploration information be better applied and developed, and provide better decision-making for the leaders.
\end{abstract}

Keywords: measurement of exploration; MapGIS; petroleum; database

\section{基於MapGIS勘探測量成果管理系統研究與設計}

\author{
陳 葉 ${ }^{1}$, 焚文有 ${ }^{2}$ \\ 中國地質大學（武漢）資訊工程學院，湖北武漢 \\ E-mail: littleaf@163.com
}

\begin{abstract}
摘 要: 在長期的石油勘探工作中，油田各單位積累了大量勘探資料，但是在積累過程中，存儲手段單 一、紙介質存儲、低效的人工管理等問題函待解決。系統基於 MapGIS，用大型資料庫 SQL Server2000 作為資料伺服器, 以 $\mathrm{B} / \mathrm{S}$ 和 $\mathrm{C} / \mathrm{S}$ 模式相結合方式運行的油氣勘探資料管理資訊系統, 通過系統資料層、 管理層、應用層的有機協調來初步實現勘探資料管理的資訊化和共用。結果顯示系統的應用會使勘探 測量成果得到更加合理的利用與開發，也能為勘探决策的及時性和準確率的提高提供更有力的支援。
\end{abstract}

關鍵字: 勘探測量; MapGIS; 石油; 資料庫

\section{1. 前 言}

在長期的石油勘探工作中, 油田各單位積累了大 量的地震、測井、鑽井、地質成果圖件等方面的勘探 資料, 這些勘探資料是石油行業工作發展重要的基礎 資訊資源；但長期以來這些資料分散在油田的各專業 部門中, 由各專業部門分別進行管理, 在存儲和開發 利用方面目前大多還基本上處於存儲手段單一、紙介 質存儲、低效的人工管理等等, 這種狀況已無法滿足
日益複雜的勘探現狀對地質資訊的需求 [1]。而在資 訊化高速發展的今天，建立統一石油勘探資料庫，對 勘探測量圖件資料進行統一管理，改變現有的資料存 儲單一, 不安全, 資料冗餘不方便查找等缺點, 實現 石油勘探圖件資料資料及時更新和維護，有效管理資 料資料，並將石油勘探成果資料與電子地圖有機結 合，更加直觀形象的展示發佈石油勘探成果，為石油 資源的進一步勘測測 量和相關技術開發提供了資料 平臺。 


\section{2. 系統建設目標}

\section{1 勘探測量圖件統一管理}

採用大型的資料庫將勘探公司測量採集生成的二 維勘探測線圖, 三維勘探測線圖, 構造圖, 地形圖, 測井圖等圖件成果進行統一的管理。支援多種檔格式 的資料與成果共用、上載、下載, 並對已有的石油勘 探成果資訊進行整理、完善和系統管理。

\section{2 建立安全用戶管理體系}

由於石油的勘探資料採集相當複雜與艱辛, 石油 部門對於資料的保密有著安全保密的要求。不同的資 料, 對於用戶有著不同操作許可權。因此, 建立安全 用戶管理體系，保證資料和系統的安全性。

\section{3 實現勘探成果發佈, 為領導決策提供強有力 支持[2]}

石油勘探資料豐富，資料通過網上發佈，用戶可 以方便的交流共用資訊內容。另外通過 MapGIS 平臺 建設實現勘探成果資料的處理和分析, 為領導決策提 供最準確，最全面的資訊服務，減輕管理者從事低層 次資訊處理和分析的負擔, 使得他們專注於最需要決 策智慧和經驗工作, 提高工作效率, 更好的為石油勘 探開發目標服務。

\section{3. 系統總體框架和結構}

系統總體分為資料層, 管理層和應用層。資料層 包括勘探測量圖件資料, 測井, 勘探測線等專業資 料, 通過大型資料庫存放各類資源。管理層重要提供 的是 MapGIS 空間資料管理, MapGISIMS 元件服
務。應用層包括對用戶提供各種應用服務。結構圖如 下圖 1 。

系統同時將 $\mathrm{C} / \mathrm{S}$ 和 $\mathrm{B} / \mathrm{S}$ 兩種模式結合起來, 充 分利用兩種架構的優勢, C/S 模式能提供安全有效 的人機交互處理能力, 資料管理部門人員通過在 $\mathrm{C} / \mathrm{S}$ 模式下對資料進行格式轉換, 編輯處理, 錄入 上載等工作。而利用 $\mathrm{B} / \mathrm{S}$ 的優勢, 又能夠在 Internet 上發佈勘探資料和提供相應資料資訊查詢, 相互取 長補短, 而且基於 $C / S$ 和 $B / S$ 兩種運行模式的系統 平臺為用戶提供了安全且高效的操作，將資料的錄 入與查詢分開, 即安全有效的管理資料, 又可通過 網路進行資料共用查詢, 為領導決策提供強有力的 支援[2]。

本系統採用大型資料庫管理系統( SQL Server2000) 作為資料管理平臺, 並運用 ODBC 來進行資料庫訪 問。使用MapGIS 的空間資料引擎來管理平臺。系統運 用於 XP, Windows2003 等作業系統, 以 $\mathrm{VC}++$, C\#等 語言來開發, 並使用 MapGIS 平臺元件及 MapGISIMS 元件支援。同時將MapGIS 元件嵌入到應用程式中, 以 OLE 方式啟動 MapGIS 實現其在後臺運行, 實現應用 程式中有關地理資訊的處理功能。

\section{4. 系統功能設計}

\section{1 測量圖件成果管理系統}

1)成果資料編輯功能:

資料錄入人員將勘探到的資料通過測量圖件成果 管理系統中提供的資料轉化, 資料校正, 資料裁剪等 工具進行資料格式和圖幅的修正，並準備入庫。同時 錄入圖件的附屬資訊。

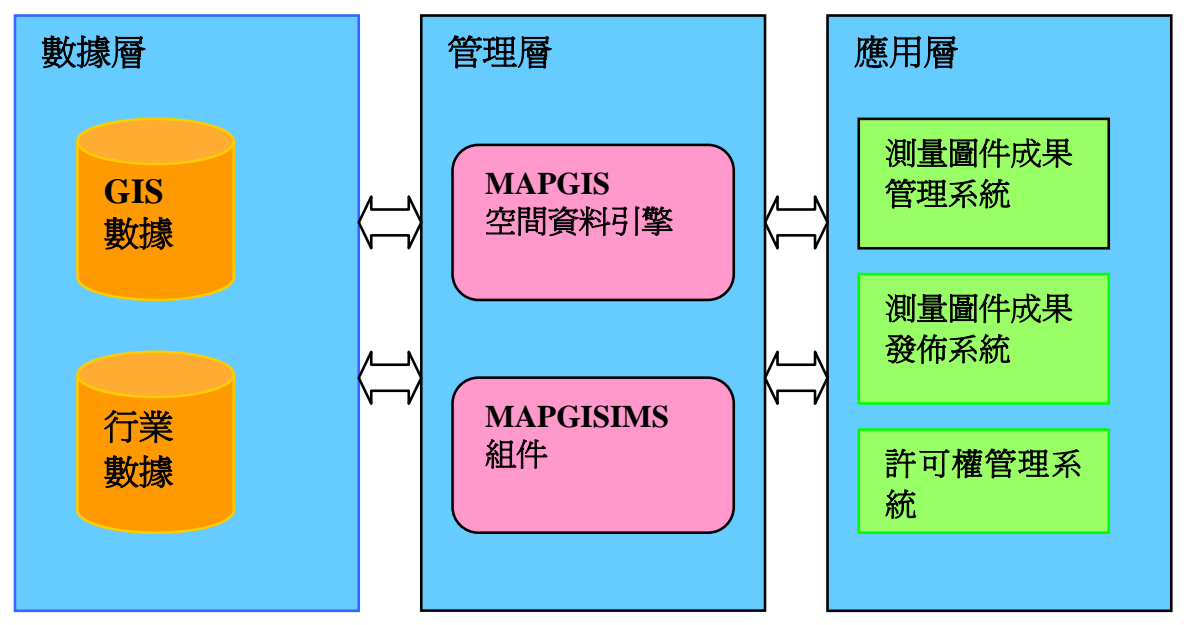

圖 1. 系統的整體框架 
2)導航圖編輯功能:

資料錄入人員可以在導航圖中錄入施工工區圖和 相應屬性資料, 還可以對其施工工區圖進行編輯, 增 強導航圖的可視性。並將勘探成果分別錄入到施工工 區對應區域。

3)疊加功能:

資料錄入人員可以通過疊加功能將成果測線與地 形圖疊加、測線與構造圖疊加、邊界與地形圖疊加、 邊界與構造圖疊加，崖生的疊加圖錄入資料庫中。

4)圖件列印功能:

測量圖件成果管理系統還提供輸出 gif, bmp, jpg 等格式列印功能。

5)管理工具功能:

提供資料轉換功能, 將 AutoCAD 格式資料轉換為 MapGIS 格式; 提供投影變換; 提供誤差校正; 提供圖 像分析: 對標準分幅的地形圖, 通過輸入圖幅號自動添 加控制點進行校正; 提供距離測量, 測量兩點之間的距 離; 提供面積測量, 測量任意不規則區域的面積。

\section{2 測量圖件成果發佈系統}

1)圖件成果查詢功能:

用戶可以通過良好的網頁介面, 通過點擊查詢導 航圖, 找到查詢的勘探工區中的勘探圖, 如三維勘探 測線圖。另外還可以通過輸入關鍵字和關鍵資訊快速 查詢到勘探圖。

2)圖件下載功能:

系統還提供了下載功能，用戶可以將查詢到的勘 探圖以 MapGIS 格式下載到本地進行編輯。

3)疊加查詢功能:

領導還可以通過我們提供的疊加分析功能, 查看 到疊加圖。通過疊加圖, 領導可以清晰地看到施工的 狀況, 計畫完成的情況。

4)成果資料統計功能:

系統通過統計功能, 統計出施工面積等基本資 訊，為施工提供資料依據。

\section{3 許可權管理系統}

用戶管理模組是每一個系統的必備的模組，它是
許可權控制管道。用戶管理模組是管理員對不同用戶 分配不同角色, 每個角色擁有不同的許可權。此系統 的許可權是通過控制功能表來控制權利的，當不同許 可權的用戶登入，他們能看的功能表是不同的。系統 功能圖如圖 2 所示。

\section{4 系統功能介面}

成果發佈系統介面，成果管理系統介面如圖 3, 4 .

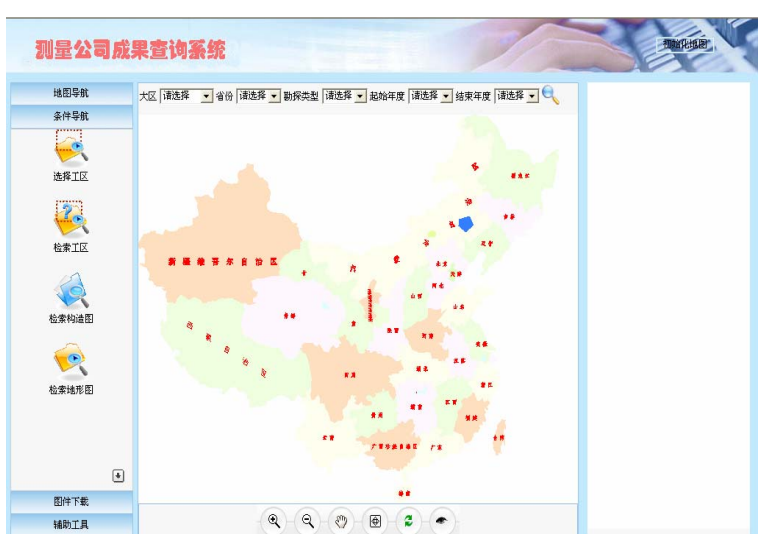

圖3. 成果發佈系統介面

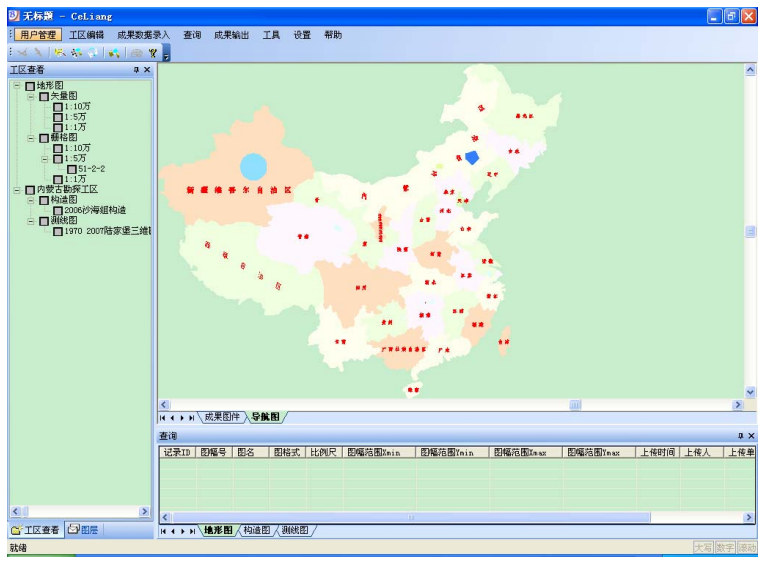

圖4. 成果管理系統介面

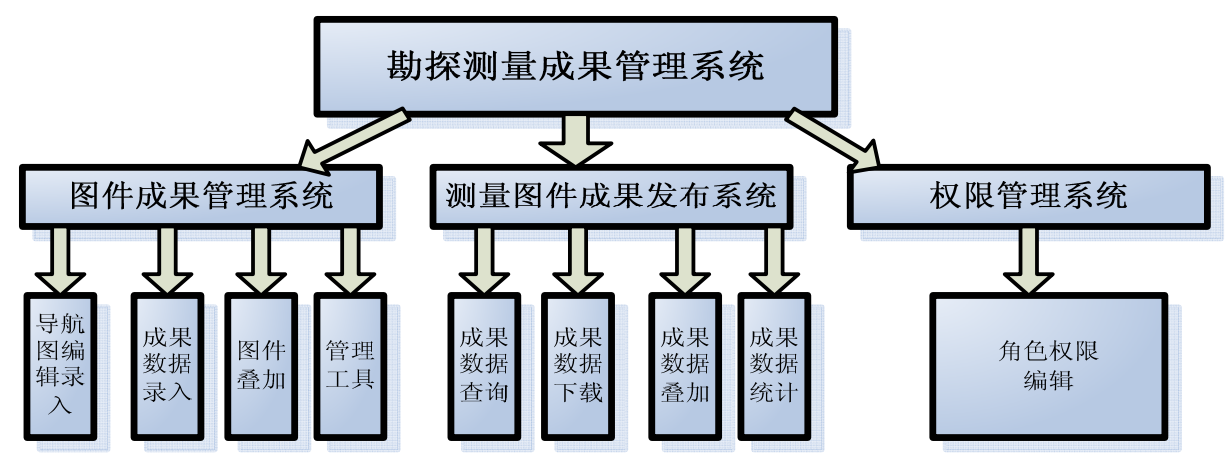

圖2. 系統功能圖 


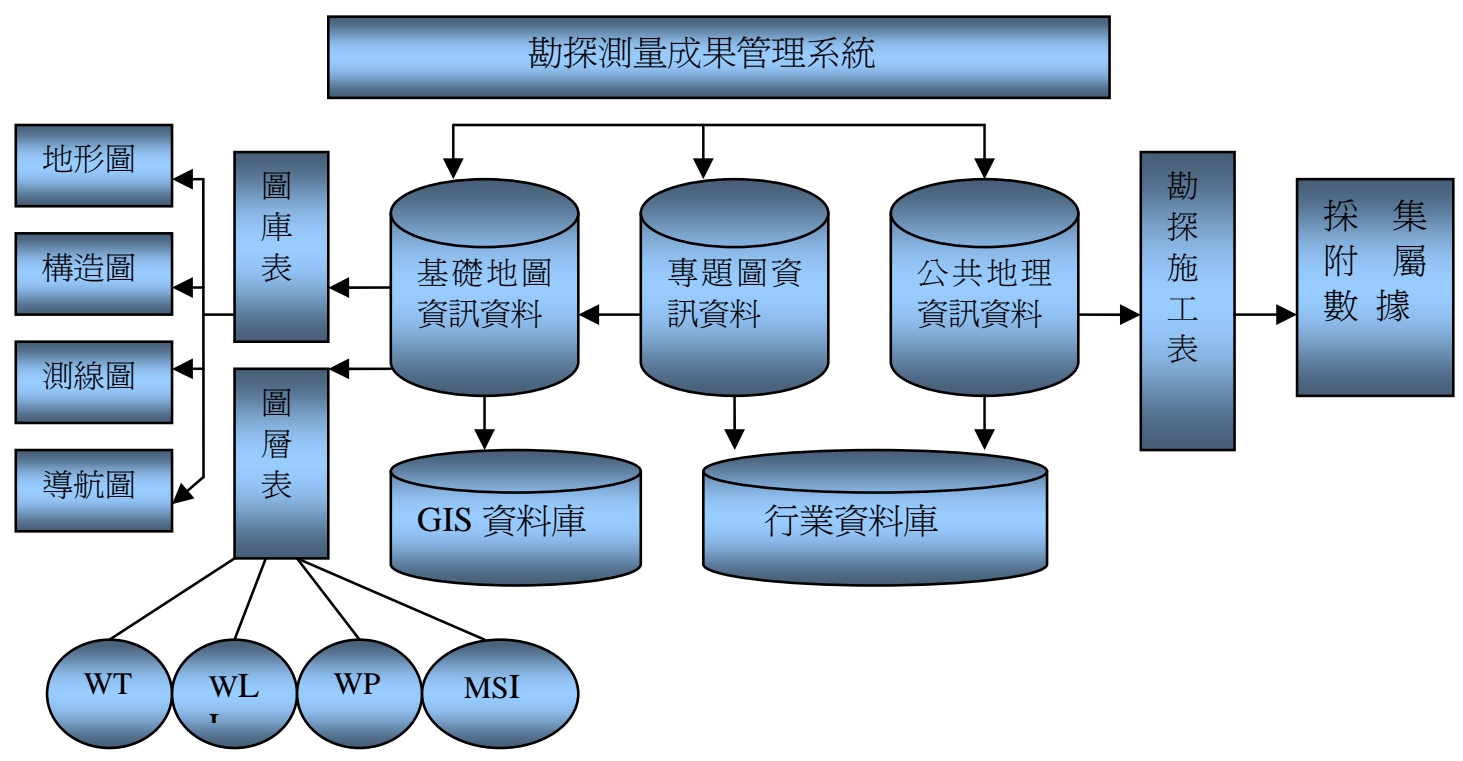

圖5. 系統資料庫架構

\section{5. 系統資料庫設計}

該系統資料庫主要分為兩大部分：一個是能夠由 MapGIS 管理的地理資訊資料。其中包括空間資訊資 料和屬性資訊資料，另一個是行業資訊資料。

\section{1 地理資訊資料}

空間資訊資料用於存放和管理基礎地形圖，實現 對不同比例尺（1：5000、1：10000、1:100000 等）和 不同檔格式 (柵格影像地形圖和向量地形圖庫) 的地 形圖進行管理。另外還存放施工導航圖。

屬性資訊資料包括基礎圖的屬性資料。系統資料 庫架構如图 5。

\section{2 行業資訊資料}

行業資訊資料目前主要包括勘探公共地理資訊資 料和勘探專題圖資料。

勘探公共地理資訊資料主要包括石油勘探開發涉 及的施工隊伍, 施工年份等的資料。該資料一般依附 於根據不同的勘探方法, 提取出與具體業務相關的資 料層, 形成針對不同來源的勘探專題型資料庫。

勘探專題圖資料則是包括二維地震勘探測線圖, 三維地震勘探測線圖, 構造圖等。如二維地震勘探測 線圖顯示地下的地質構造情況, 同時幾十條相交的二 維測線共同使用, 即可編制出地下某地質時期沉積前 地表的起伏情況。如果發現哪些地方可能儲有油氣, 則可確定其為油氣鑽探井位。

\section{3 數據組織關係}

基礎地形資訊資料和專題圖資訊資料中的圖形 都是以 MapGIS 支援分別以點, 線, 區, 和 MSI 等 圖格式存放在圖層表中。系統的地理資料和專題資 料圖的屬性資料都存放在圖庫表中。為了資料能最 大的存入庫又不產生冗餘, 我們將圖索引表又分成 了地形圖索引表, 構造圖索引表, 測線圖索引表。 各表中同時存放地形圖, 構造圖, 測線圖勘探出的 資料。每張專題圖都在圖索引中有相應的編碼, 編 碼是依據專題圖不同比例尺, 圖幅類型, 施工工區 等勘探公共地理資訊資料的不同而制定的。這些資 料都存放在勘探施工表裏。圖庫表與圖層表是 $1: \mathrm{N}$ 的關係。

\section{6. 結束語}

石油勘探資料的管理與應用是一項龐大的系統工 程, 需要構築扎實的基礎, 綜合應用各種先進的技 術。MapGIS 平臺在石油領域有著自己的基礎平臺, 並且圍繞專業圖件編繪、資料庫管理、石油勘探開發 生產管理、石油管道管理、石油儲量管理、地面建設 等領域深入應用, 能為石油行業提供全面的優秀資訊 管理解決方案。通過基於 MapGIS 的勘探成果管理系 統對勘探圖件進行管理, 提高勘探研究效率, 降低勘 探成本，提高勘探決策的及時性和準確率，搶救歷史 資料, 保護資料資產。必將促進“數字油田”的建設, 並將帶來巨大的經濟效益。 


\section{參考文獻 (References)}

[1] 楊紅梅. ArcGIS 下的油田勘探資料管理方案[J]. 世界 地質, 2003, 22(2): 201-214.

[2] 魏蓮等. 基於 GIS 的石油勘探資訊系統[J]. 測繪科學, 2007, 5 .
[3] 吳信才等. 地理資訊系統原理與方法. 電子工業出版 社, 2002.

[4] 孟令奎, 史文中, 張鵬林. 網路地理資訊系統原理與技 術. 科學出版社, 2005. 
